\title{
In Vitro Autonomous Construction of the Flagellar Axial Structure in Inverted Membrane Vesicles
}

\author{
Hiroyuki Terashima ${ }^{1,2}$, Chinatsu Tatsumi ${ }^{2}$, Akihiro Kawamoto ${ }^{3,+}{ }^{\mathbb{D}}$, Keiichi Namba ${ }^{3,4,5}$ (D), \\ Tohru Minamino ${ }^{3}$ and Katsumi Imada ${ }^{2, * i}$ \\ 1 Division of Biological Science, Graduate School of Science, Nagoya University, Furo-cho, Chikusa-Ku, \\ Nagoya 464-8602, Japan; terashima.hiroyuki@h.mbox.nagoya-u.ac.jp \\ 2 Department of Macromolecular Science, Graduate School of Science, Osaka University, 1-1 Machikaneyama, \\ Toyonaka, Osaka 560-0043, Japan; tatsumic14@gmail.com \\ 3 Graduate School of Frontier Biosciences, Osaka University, 1-3 Yamadaoka, Suita, Osaka 565-0871, Japan; \\ kawamoto@protein.osaka-u.ac.jp (A.K.); keiichi@fbs.osaka-u.ac.jp (K.N.); tohru@fbs.osaka-u.ac.jp (T.M.) \\ 4 RIKEN SPring-8 Center and Center for Biosystems Dynamic Research, 1-3 Yamadaoka, Suita, \\ Osaka 565-0871, Japan \\ 5 JEOL YOKOGUSHI Research Alliance Laboratories, Osaka University, 1-3 Yamadaoka, Suita, \\ Osaka 565-0871, Japan \\ * Correspondence: kimada@chem.sci.osaka-u.ac.jp; Tel.: +81-6-6850-5455 \\ + Current Affiliation: Institute for Protein Research, Osaka University, 3-2 Yamadaoka, Suita, \\ Osaka 565-0871, Japan.
}

Received: 16 December 2019; Accepted: 9 January 2020; Published: 11 January 2020

\begin{abstract}
The bacterial flagellum is a filamentous organelle extending from the cell surface. The axial structure of the flagellum consists of the rod, hook, junction, filament, and cap. The axial structure is formed by axial component proteins exported via a specific protein export apparatus in a well-regulated manner. Although previous studies have revealed the outline of the flagellar construction process, the mechanism of axial structure formation, including axial protein export, is still obscure due to difficulties in direct observation of protein export and assembly in vivo. We recently developed an in vitro flagellar protein transport assay system using inverted membrane vesicles (IMVs) and succeeded in reproducing the early stage of flagellar assembly. However, the late stage of the flagellar formation process remained to be examined in the IMVs. In this study, we showed that the filament-type proteins are transported into the IMVs to produce the filament on the hook inside the IMVs. Furthermore, we provide direct evidence that coordinated flagellar protein export and assembly can occur at the post-translational level. These results indicate that the ordered construction of the entire flagellar structure can be regulated by only the interactions between the protein export apparatus, the export substrate proteins, and their cognate chaperones.
\end{abstract}

Keywords: bacterial flagellum; type III secretion system; flagellar specific export apparatus; inverted membrane vesicle; in vitro reconstitution; flagellar filament; Salmonella typhimurium

\section{Introduction}

The bacterial flagellum is a tubular organelle extending out from the cell surface, and is rotated by a nano-scale rotary motor embedded in the cytoplasmic membrane. Flagellar construction starts with the assembly of the basal structure containing the MS-ring, the C-ring, and the flagellar protein export apparatus in the cytoplasmic membrane, followed by assembly of the filamentous axial structure composed of the rod, the hook, the hook-filament junction, the filament, and the filament cap on the basal structure (Figure 1A) [1-3]. A certain copy number of component proteins assemble into each substructure in a specific order [1]. The axial proteins are transported via the flagellar export 
apparatus, which belongs to the type III secretion system family, into the central channel of the growing tubular axial structure and diffuse through it to the distal end, where they are incorporated into the structure [4,5]. The export apparatus consists of a transmembrane export gate composed of FlhA, FlhB, FliP, FliQ, and FliR, and a cytoplasmic ATPase complex composed of FliH, FliI, and FliJ [1-3]. The MS-ring and the C-ring function as a housing for the export gate and a sorting platform for the cytoplasmic ATPase complex, respectively [6,7].

A

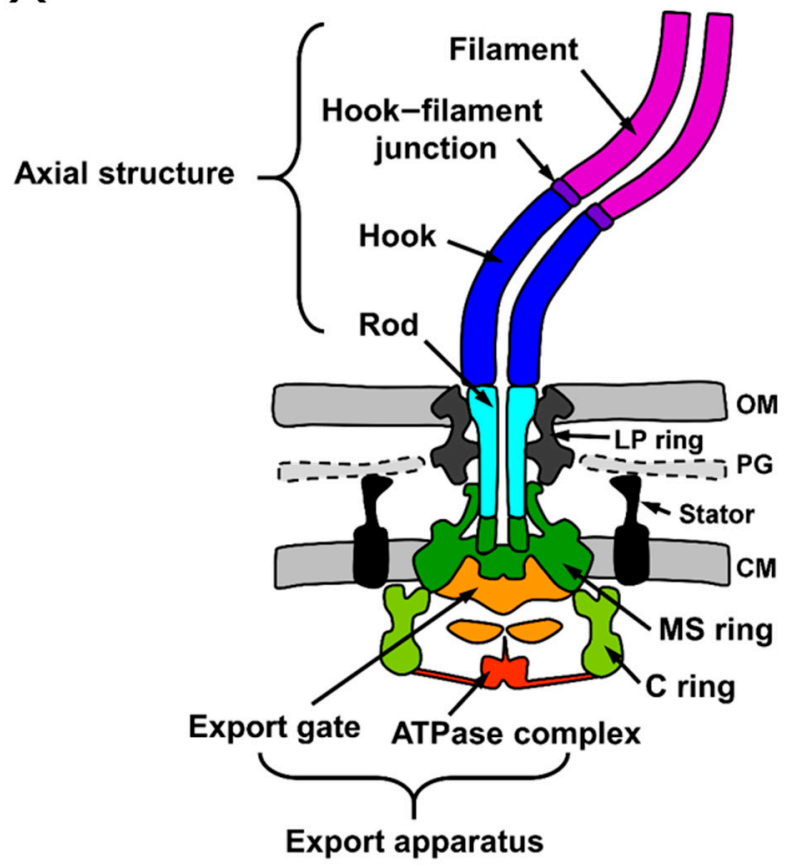

B

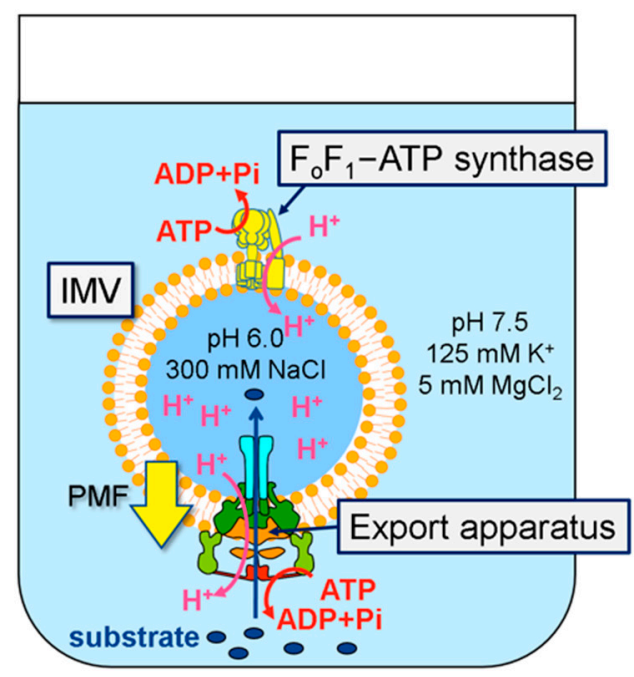

Figure 1. Schematic drawing of the Salmonella flagellum (A) and the in vitro transport assay system using the inverted membrane vesicles (IMVs) (B). (A) The sub-structures of the Salmonella flagellum are represented in the following colors: the transmembrane export gate, orange; the cytoplasmic ATPase complex, red; the MS-ring, green; the C-ring, light green; the rod, cyan; the hook, blue; the hook-filament junction, purple; the filament, magenta; the LP ring, gray; the stator, black. The core of the export apparatus consists of the export gate and the ATPase complex. The filamentous part composed of the rod, the hook, the hook-filament junction and the filament are called the flagellar axial structure. CM, the cytoplasmic membrane; PG, the peptidoglycan layer; OM, the outer membrane. (B) To apply the initial PMF to the IMVs, the IMVs were filled with $300 \mathrm{mM} \mathrm{NaCl}$ at pH 6.0 and suspended in solution with $125 \mathrm{mM} \mathrm{K}^{+}$and $5 \mathrm{mM} \mathrm{MgCl}_{2}$ at $\mathrm{pH}$ 7.5. The export substrates, ATP- $\mathrm{Mg}^{2+}$, the $\mathrm{FliH}_{2} / \mathrm{FliI}_{\text {complex, }}$ and FliJ were added to the assay mixture. To maintain PMF across the inverted membrane, endogenous $\mathrm{F}_{\mathrm{o}} \mathrm{F}_{1}$-ATP synthase pumps proton into the IMVs by ATP hydrolysis energy. PMF and ATP hydrolysis energy generated by FliI ATPase drives the substrate protein transport into the IMVs.

Flagellar construction is a well-regulated process, in which the expression and export of flagellar axial proteins are coupled with the assembly state of the flagellum. The flagellar axial proteins are classified into two groups by the substrate-recognition mode of the flagellar protein export apparatus: one is the rod/hook-type substrate class, responsible for the assembly of the rod and hook structures, and the other is the filament-type substrate class, required for the construction of the hook-filament junction, the filament, and the filament cap. Before completion of the hook (the early stage of flagellar formation), only the rod/hook-type proteins are allowed to be exported, and the export of filament-type proteins is suppressed [8,9]. After the length of the hook has reached approximately $55 \mathrm{~nm}$, the export of rod/hook-type proteins is stopped, and the filament-type proteins begin to be exported (the late stage of flagellar formation) [10-12]. Thus, the switching of the substrate specificity of the flagellar protein export apparatus from the rod/hook-type to the filament-type proteins is a crucial step in 
regulating the flagellar construction, as well as in controlling the hook length. The hook length is monitored by a secreted molecular ruler protein, FliK $[13,14]$. FliK is a rod/hook-type protein and is infrequently exported during hook assembly to measure the hook length using its N-terminal disordered region $[15,16]$. When the hook length is too short, FliK is secreted out into the extracellular media. When the hook length reaches approximately $55 \mathrm{~nm}$, the C-terminal domain of FliK binds to FlhB, one of the export gate component proteins, to induce conformational changes of FlhB and FlhA to switch the substrate specificity of the export apparatus [17-22]. The filament-type proteins form a complex with their specific cognate chaperones, which prevent premature aggregation and/or proteolysis of their cognates and help them associate with the flagellar protein export apparatus in the cytoplasm [23-25]. The flagellar chaperones not only facilitate the docking of their cognate filament-type proteins to the protein export apparatus, but also regulate the export order through the interactions with FlhA, FliI, and FliJ [1,2]. Moreover, the flagellar chaperones are multifunctional proteins able to control the production of flagellar proteins as well as delivering their cognates to the export apparatus [26-28].

Genetic and biochemical studies have revealed that there are several morphological checkpoints involved in coordination of flagellar protein export and assembly, not only at the gene expression level but also at the post-translational level. However, the molecular mechanism of each process, including protein export, is still unclear because of difficulties in direct observation of protein export and assembly in vivo. To overcome this problem, we recently established an in vitro flagellar protein transport assay system using inverted membrane vesicles (IMVs) to quantitatively control and measure protein export and monitor the flagellar assembly process (Figure 1B) $[29,30]$. We demonstrated that the flagellar protein export apparatus in the IMVs maintains the export function for rod/hook-type proteins at a level similar to that in a living cell, and that ATP hydrolysis by FliI ATPase dramatically accelerates the export of rod/hook-type proteins. Proton-motive force (PMF) across the cytoplasmic membrane is a primary driving force for flagellar protein export [31-33], and the energy derived from ATP hydrolysis by FliI ATPase is thought to be required for the activation of the PMF-driven export gate complex [34]. However, our study with IMVs revealed that the energy of ATP hydrolysis is able to drive protein export even when PMF is absent [29]. Moreover, we successfully reproduced not only hook formation inside the IMVs, but also hook length control. However, we have not yet shown the export of the filament-type proteins via the switched export apparatus in the IMVs. Since the filament-type proteins require their specific cognate chaperones for efficient export [2], the protein export mechanism, including its regulation, would be expected to be different from that for the rod/hook-type proteins.

Here, we showed that the filament-type substrates (FlgK, FlgL, FliC, FliD) in complex with their cognate chaperones are transported into the interior of the IMVs after completion of the hook. These transported filament-type proteins assemble into the filament at the tip of the hook. Moreover, even when the hook-type proteins (FlgD, FlgE, FliK) and filament-type proteins in complex with substrate-specific flagellar chaperones were simultaneously added to the in vitro transport assay solutions, these proteins autonomously and sequentially assembled into the normal flagellar structure, indicating that the coupling of flagellar gene expression with assembly is not really required for well-ordered flagellar formation.

\section{Materials and Methods}

\subsection{Bacteria Strains and Plasmids}

Bacterial strains and plasmids used are listed in Table 1. The primers used in this study are shown in Supplementary Table S1. Salmonella and Escherichia coli cells were cultured in LB broth $(1 \%(w / v)$ bactotryptone, $0.5 \%(w / v)$ yeast extract, $0.5 \%(w / v) \mathrm{NaCl})$. Chloramphenicol was added to a final concentration of $30 \mu \mathrm{g} / \mathrm{mL}$. Ampicillin was added to a final concentration of $50 \mu \mathrm{g} / \mathrm{mL}$. 
Table 1. Bacterial strains and plasmids.

\begin{tabular}{|c|c|c|}
\hline Strain or Plasmid & Genotype or Description & Reference \\
\hline \multicolumn{3}{|c|}{ E. coli strains } \\
\hline DH5 $\alpha$ & $\mathrm{F}^{-}$, mcrA,$\Delta\left(\right.$ mrr-hsdRMS-mcrBC), $\Phi 80 \mathrm{~d} l a c Z \Delta \mathrm{M} 15, \Delta l a c X 74$, deoR, recA1, araD139, $\Delta($ ara leu $) 7697$, galU, galK,$\lambda^{-}$, rpsL, endA1,nupG & \\
\hline BL21(DE3) & $\mathrm{F}^{-}$ompT hsdS $\mathrm{S}_{\mathrm{B}}\left(\mathrm{r}_{\mathrm{B}}{ }^{-} \mathrm{m}_{\mathrm{B}}{ }^{-}\right)$gal dcm (DE3) & Novagen \\
\hline \multicolumn{3}{|c|}{ Salmonella strains } \\
\hline STH001 & $\Delta f l h B \Delta f l g D \Delta f l i T$ & [29] \\
\hline \multicolumn{3}{|c|}{ Plasmids } \\
\hline pBAD33SD & $\mathrm{Cm}^{\mathrm{r}}, \mathrm{pBAD} 33-$ based vector substituted NheI and EcoRI sites (GCTAGCGAATTC) into SD sequence (GCAGGAGGATTC) & [29] \\
\hline pTrc99a & Amp ${ }^{r}, P_{\text {trc }}$ expression vector & \\
\hline pTrc99aNde & pTrc99a-based vector substituted NcoI sites (cagACCATGgaa) into NdeI sequence (cagCATATGgaa) & This study \\
\hline pET3c & $\mathrm{Amp}^{\mathrm{r}}, \mathrm{T} 7$ expression vector & Novagen \\
\hline pET15b & Amp ${ }^{\mathrm{r}}$, T7 expression vector & Novagen \\
\hline pITH103 & pBAD33SD-flhB + flhDC (FlhB, FlhD/FlhC) & [29] \\
\hline pITH105 & pET15b-flgD (His-FlgD) & [29] \\
\hline pITH106 & pET15b-flgE (His-FlgE) & [29] \\
\hline pMMIJ001 & pET15b-flij (His-FliJ) & [35] \\
\hline pMKM1702iH & pTrc99a-his-fliI + fliH (FliH/His-FliI), his-fliI was derived from the pET19b-based plasmid, pMM1901. & [36] \\
\hline pITH107 & pET15b-fliK (His-FliK) & [29] \\
\hline pITH108 & pET3c-fliS (FliS), the fliS gene amplified by PCR was cloned into the NdeI and BamHI sites of the pET3c vector & This study \\
\hline pITH109 & pET15b-fliC (His-FliC), the fliC gene amplified by PCR was inserted into the NdeI and BamHI sites of pET15b & This study \\
\hline pITH110 & $\begin{array}{l}\text { pTrc99aNde-fliS + his-fliC (His-FliC/FliS), fliS derived from pITH108 and his-fliC derived from pITH109 were inserted into the NdeI and BamHI sites, and the XbaI and HindIII } \\
\text { sites of pTrc99aNde, respectively }\end{array}$ & This study \\
\hline pITH111 & pET3c-fliT (FliT), the fliT gene amplified by PCR was cloned into the NdeI and BamHI sites of pET3c & This study \\
\hline pITH112 & pET15b-fliD (His-FliD), the fliD gene amplified by PCR was inserted into the NdeI and BamHI sites of pET15b & This study \\
\hline pITH113 & $\begin{array}{l}\text { pTrc99aNde-fliT + his-fliD (His-FliD/FliT), fliT derived from pITH111 and his-fliD derived from pITH112 were subcloned into the NdeI and BamHI sites and the XbaI and HindIII } \\
\text { sites of pTrc99aNde, respectively }\end{array}$ & This study \\
\hline pMMGN110 & pET22b-flgN (FlgN), The flgN gene amplified by PCR was cloned into the NdeI and BamHI sites of pET22b & [37] \\
\hline pMMGN300 & pET19b-flgN (His-FlgN), flgN derived from pMMGN110 was subcloned into the NdeI and BamHI sites of pET19b & This study \\
\hline pMMGK130 & pET15b-flgK (His-FlgK), the flgK gene amplified by PCR was inserted into the NdeI and BamHI sites of pET15b & [37] \\
\hline pITH116 & pET15b-flgL (His-FlgL), the flgL amplified by PCR was inserted into the NdeI and BamHI sites of pET15b & This study \\
\hline pITH117 & $\begin{array}{l}\text { pTrc99aNde-flgN + his-flgK (His-FlgK/FlgN), flgN derived from pMMGN300 and his-flgK derived from pMMGK130 were subcloned into the NdeI and BamHI sites and the XbaI } \\
\text { and HindIII sites of pTrc99aNde, respectively }\end{array}$ & This study \\
\hline pITH118 & $\begin{array}{l}\text { pTrc99aNde-flgN + his-flgL (His-FlgL/FlgN), flgN derived from pMMGN300 and his-flgL derived from pITH116 were subcloned into the NdeI and BamHI sites and XbaI and } \\
\text { HindIII sites of pTrc99aNde, respectively }\end{array}$ & This study \\
\hline
\end{tabular}




\subsection{Preparation of Inverted Membrane Vesicles}

The inverted membrane vesicles (IMVs) were prepared according to the method described by Terashima et al. [29]. We prepared the IMVs from a Salmonella cell strain STH001 $(\Delta \mathrm{flhB}, \Delta$ flgD, and $\Delta$ fliT) harboring plasmid pITH103 (wild-type flhB and flhDC). The cells were cultured at $37^{\circ} \mathrm{C}$ for $9 \mathrm{~h}$, inoculated into $1 \mathrm{~L}$ of LB broth with $1 / 100$ dilution and cultured at $30^{\circ} \mathrm{C}$ for $1 \mathrm{~h}$. L-arabinose was then added at the final concentration of $0.02 \%(w / v)$ for induction of $\mathrm{FlhB}$ and $\mathrm{FlhD}_{4} / \mathrm{FlhC}_{2}$, and the culture was continued at $18^{\circ} \mathrm{C}$ for $12-16 \mathrm{~h}$ until $\mathrm{OD}_{600}$ reached around 1.5 . The cells were collected by centrifugation and suspended in $75 \mathrm{~mL}$ of sucrose solution (10 mM Tris- $\mathrm{HCl} \mathrm{pH}$ 8.0, 0.75 M sucrose), to which was added $22.5 \mathrm{mg}$ of lysozyme powder. Next, $150 \mathrm{~mL}$ of $1.5 \mathrm{mM}$ EDTA-NaOH pH 8.0 was poured into the cell suspension on ice to form spheroplasts. The cell suspension was stirred on ice for $1 \mathrm{~h}$. The spheroplasts were collected at 5000× $g$ for $10 \mathrm{~min}$ and suspended in $25 \mathrm{~mL}$ solution A (20 mM MES-NaOH pH 6.0, $300 \mathrm{mM} \mathrm{NaCl}$ ) with a half tablet of protease inhibitor cocktail (cOmplete EDTA-free, Roche). In order to produce IMVs, the cell suspension was passed through high-pressure cell homogenizer (STANSTED) at $90 \mathrm{MPa}$. After centrifugation at 20,000× $\mathrm{g}$ for $10 \mathrm{~min}$ to remove cell debris, the membrane vesicles were precipitated by ultra-centrifugation at $100,000 \times g$ for $1 \mathrm{~h}$. The crude IMVs were suspended in $1 \mathrm{~mL}$ of solution A and separated by sucrose density-gradient centrifugation $(60 \%(w / w) 5 \mathrm{~mL} / 50 \%(w / w) 9 \mathrm{~mL} / 45 \%(w / w) 9 \mathrm{~mL} / 40 \%(w / w) 6 \mathrm{~mL}$ stepwise gradient in the Beckman ultra-clear tube) at 60,000× $g$ (SW32 Ti rotor: Beckman, Brea, CA, USA) for $16 \mathrm{~h}$. A brown-colored layer fraction containing the IMVs was recovered, and the IMVs were precipitated by ultra-centrifugation at $100,000 \times g$ for $1 \mathrm{~h}$. The precipitant was suspended in $900 \mu \mathrm{L}$ of solution A. The suspension was divided into $300 \mu \mathrm{L}$ aliquots, frozen with liquid nitrogen and stored at $-80^{\circ} \mathrm{C}$. The frozen stock was thawed and filtered with a $0.8 \mu \mathrm{m}$ polycarbonate filter (Nuclepore membrane PC MB $190.8 \mathrm{U}$, GE healthcare, Chicago, IL, USA). The filtered solution was loaded onto a Sephadex G-50 fine column (GE healthcare) and eluted with solution $\mathrm{B}(125 \mathrm{mM} \mathrm{KCl}, 20 \mathrm{mM}$ Tris- $\mathrm{HCl} \mathrm{pH}$ 7.5). The concentration of IMVs was adjusted to give OD $600 \mathrm{~nm}=0.1$.

\subsection{Protein Purification}

FlgD, FlgE, FliK, the FliH 2 /FliI complex, and FliJ were purified according to the method described by Terashima et al. [29]. The FliC/FliS, FliD/FliT, FlgK/FlgN, or FlgL/FlgN complex was expressed in E. coli BL21(DE3) cells from the plasmids pITH110, pITH113, pITH117, or pITH118, respectively. The cells harboring pITH110 or pITH117 were inoculated directly from the colonies onto the agar plate into LB broth and incubated overnight at $30^{\circ} \mathrm{C}$ to express the proteins by leak-expression from pTrc99a-based plasmids. The cells harboring pITH113 or pITH118 were grown at $30^{\circ} \mathrm{C}$ for overnight, inoculated into fresh LB broth with $1 / 100$ dilution and cultured at $30^{\circ} \mathrm{C}$ until the optical density at $600 \mathrm{~nm}$ reached $0.5-0.8$. IPTG was then added to the final concentration of $0.1 \mathrm{mM}$, and the culture was continued at $18{ }^{\circ} \mathrm{C}$ for overnight. The cells expressing FliC/FliS, FliD/FliT, FlgK/FlgN, or FlgL/FlgN were suspended in cell-suspend solution $(50 \mathrm{mM}$ Tris- $\mathrm{HCl}$ pH 8.0, $500 \mathrm{mM} \mathrm{NaCl})$ containing protease inhibitor cocktail (cOmplete EDTA-free, Roche, Rotkreuz, Switzerland), and disrupted by sonication. After removal of cell debris by low-speed centrifugation followed by filtration with a $0.45 \mu \mathrm{m}$ cellulose acetate membrane filter device, the cell lysate was loaded to a HisTrap HP column (GE healthcare), and the hexahistidine-tagged proteins were then eluted by linear imidazole gradient. To chop off the hexahistidine tag, protein solutions were incubated with thrombin (GE healthcare) at room temperature for $3 \mathrm{~h}$ and then passed through HisTrap HP again to remove hexahistidine-tag-retained proteins. Finally, the protein solution was purified using a Superdex 200 column (GE healthcare) equilibrated with external solution (20 mM Tris- $\mathrm{HCl}$ pH 7.5, $125 \mathrm{mM} \mathrm{KCl}$ ). The purity of the purified proteins was examined by SDS-PAGE and Coomassie Brilliant Blue staining (Supplementary Figure S1).

\subsection{Transport Assay}

Transport assay of the hook-type proteins was carried out as previously described [29]. Transport assay of the filament-type proteins were carried out using the IMVs after hook formation by the transport reaction. FlgD, FlgE, FliK, FliJ, and the $\mathrm{FliH}_{2} /$ FliI complex were added into the IMV solution 
(20 mM Tris- $\mathrm{HCl}, \mathrm{pH} 7.5,125 \mathrm{mM} \mathrm{KCl}, 5 \mathrm{mM} \mathrm{MgCl}_{2}$, and $1 \mathrm{mM}$ dithiothreitol (DTT)) at the final concentration of $4 \mu \mathrm{M}, 4 \mu \mathrm{M} 4 \mu \mathrm{M}, 0.25 \mu \mathrm{M}$, and $1.5 \mu \mathrm{M}$, respectively. After addition of ATP with a final concentration of $5 \mathrm{mM}$, the mixture was incubated at $37^{\circ} \mathrm{C}$ for $1 \mathrm{~h}$ to form the hook in the IMVs and then was ultra-centrifuged at $100,000 \times g$ for $30 \mathrm{~min}$. The precipitant was washed by external solution and the solution was removed. The precipitant was resuspended in $100 \mu \mathrm{L}$ of external solution and used for the filament-type protein transport assay. The IMV solution was incubated with the filament-type proteins $(2 \mu \mathrm{M})$, FliJ $(0.25 \mu \mathrm{M})$, the $\mathrm{FliH}_{2} / \mathrm{FliI}$ complex $(1.5 \mu \mathrm{M}), \mathrm{MgCl}_{2}(5 \mathrm{mM})$, and ATP $(5 \mathrm{mM})$ at $37^{\circ} \mathrm{C}$ for $2 \mathrm{~h}$. The proteins transported in the IMVs were detected by immunoblotting.

\subsection{Purification of the Hook-Basal Body from IMV}

The hook-basal body complexes were purified according to the method described by Terashima et al. [29]. The IMV was solubilized by $0.1 \%(v / v)$ Triton X-100. The suspension was ultra-centrifuged at $150,000 \times g$ for $30 \mathrm{~min}$. The filament-hook-basal body complex was precipitated and suspended in TET solution (10 mM Tris-HCl pH 8.0, $1 \mathrm{mM}$ EDTA, 0.1\% (v/v) Triton X100). In order to completely dissolve the membrane, the suspension was mixed with $1 \mathrm{~mL}$ of alkali solution $(10 \%(w / v)$ sucrose, $0.1 \%(v / v)$ Triton X100, $0.1 \mathrm{M} \mathrm{KCl}$, adjusted to $\mathrm{pH} 11.0$ by $\mathrm{KOH})$. The suspension was layered on $1 \mathrm{~mL}$ of $35 \%(w / v)$ sucrose solution prepared by dissolving sucrose in TET solution in an ultra-centrifuge tube. After incubation on ice for $30 \mathrm{~min}$, the suspension was ultra-centrifuged at 38,000 rpm (Beckman TLA100.3 rotor) for $30 \mathrm{~min}$ to precipitate the filament-hook-basal body. The precipitates were suspended in TET solution and then observed by electron microscopy.

\subsection{Dynamic Light Scattering}

A total $12 \mathrm{uL}$ of purified IMVs in solution B (OD $600 \mathrm{~nm}=0.1)$ was injected into a low-volume quartz cuvette and measured using Zetasizer $\mu V$ (Malvern Panalytical, Malvern, UK). The scattering data were analyzed using Zetasizer software (Malvern Panalytical).

\subsection{Negative-Staining Electron Microscopy}

Sample solutions were applied to carbon-coated copper grids and negatively stained with $2.0 \%$ $(w / v)$ phosphotungstic acid or $2.0 \%(w / v)$ uranyl acetate. Images were observed with a JEM-1010 transmission electron microscope (JEOL, Tokyo, Japan) operating at $100 \mathrm{kV}$ using a BIOSCAN model 792 CCD camera, a JEM-1011 transmission electron microscope (JEOL, Tokyo, Japan) operating at $100 \mathrm{kV}$ using a TVIPS TemCam-F114 CCD camera or a TemCam-F415 CCD camera, or a JEM-2010 transmission electron microscope (JEOL, Tokyo, Japan) operating at $200 \mathrm{kV}$ using a Orius SC200D model 833 CCD camera (Gatan, Pleasanton, CA, USA).

\section{Results}

\subsection{In Vitro Protein Transport of the Filament-Type Proteins into the IMVs}

We previously showed that FlgE, FlgD, and FliK, which belong to the rod/hook-type substrate class, are transported into the IMVs through the flagellar protein export apparatus to form the hook on the endogenous rod in the basal body inside the IMVs [29]. The transported FlgE molecules were assembled into the hook with the help of the FlgD cap, and the hook length was controlled to approximately $55 \mathrm{~nm}$ by the addition of FliK to the assay solutions. These results suggested that the FliK molecule alone is sufficient the hook length control, and terminates the export of the rod/hook-type proteins in the in vitro protein transport assay system [29]. However, we had not examined whether FliK actually induces the switching of substrate specificity of the flagellar protein export apparatus from the rod/hook-type to the filament-type proteins. We therefore studied the export of the filament-type proteins into the IMVs after the termination of rod/hook-type protein export triggered by FliK.

We first incubated IMVs with the substrate proteins required for hook formation (FlgD, FlgE, and FliK), the cytoplasmic ATPase complex proteins (the $\mathrm{FliH}_{2} / \mathrm{FliI}$ complex and FliJ), ATP, and $\mathrm{Mg}^{2+}$ for 
$1 \mathrm{~h}$ at $37^{\circ} \mathrm{C}$ to form the hook in the IMVs, as previously described [29]. The IMVs were precipitated by ultra-centrifugation and then used for in vitro transport assays for the filament-type proteins. The IMVs with the hook-basal bodies were suspended into transport assay mixtures containing the FlgN/FlgK, FlgN/FlgL, FliS/FliC, and FliT/FliD chaperone-substrate complexes and the components of the cytoplasmic ATPase complex. The mixtures were then incubated for $2 \mathrm{~h}$ at $37^{\circ} \mathrm{C}$ after adding ATP and $\mathrm{Mg}^{2+}$. FlgK, FlgL, FliC, and FliD were transported into the IMVs, but were not transported in the absence of either FliK or FlgE (Figure 2). These results indicate that both FliK and the presence of the completed hook structure are required for the export of the filament-type proteins into the IMVs. Therefore, we suggest that purified FliK alone triggers switching of the substrate specificity of the flagellar protein export apparatus upon completion of hook assembly.

A

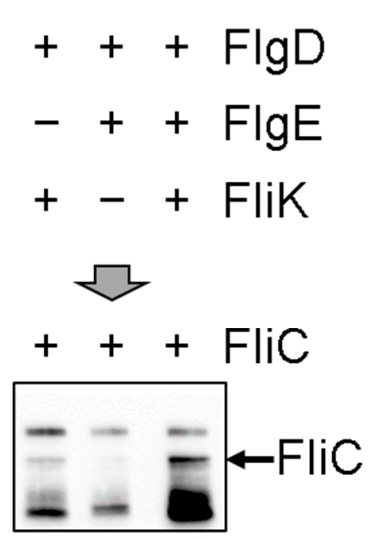

C

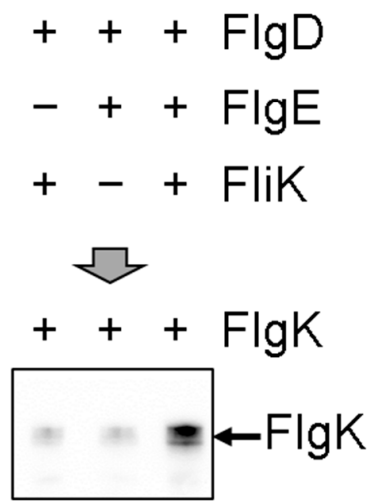

B

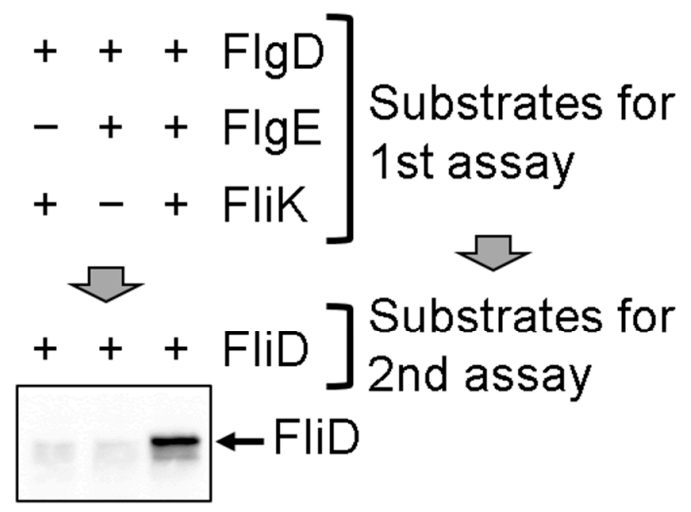

D

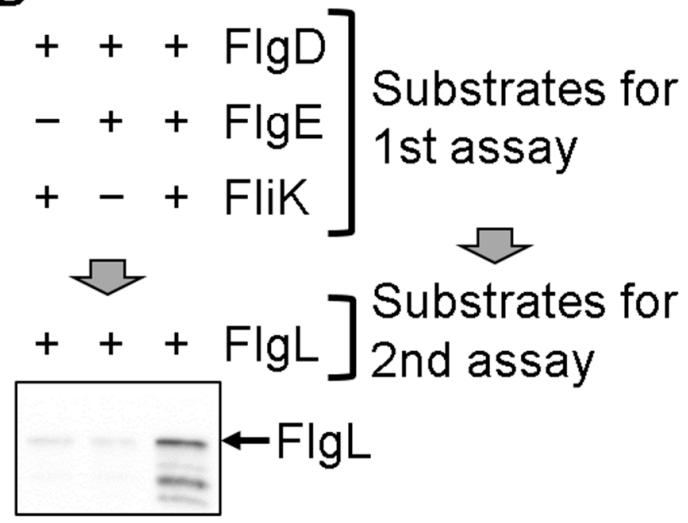

Figure 2. Hook formation is essential for the filament-type protein transport. The first reaction mixture for hook formation contained $\mathrm{FlgD}$, the $\mathrm{FliH}_{2}$ /FliI complex, FliJ, and ATP at final concentrations of $4 \mu \mathrm{M}, 1.5 \mu \mathrm{M} 0.25 \mu \mathrm{M}$, and $5 \mathrm{mM}$, respectively. FlgE and FliK were added to the mixture at the final concentration of $4 \mu \mathrm{M}$, respectively. The first transport reaction was carried out at $37^{\circ} \mathrm{C}$ for $1 \mathrm{~h}$. After the reaction, the IMVs were precipitated by ultra-centrifugation $(100,000 \times g, 30 \mathrm{~min})$ and used for the second transport reaction to transport the filament-type substrates. Re-suspended IMVs were mixed in the second transport reaction mixture containing $1.5 \mu \mathrm{M}$ of the $\mathrm{FliH}_{2} /$ FliI complex, $0.25 \mu \mathrm{M}$ of FliJ, $5 \mathrm{mM}$ of ATP-Mg, and $2 \mu \mathrm{M}$ of the filament-type substrate-chaperone complex: FliC/FliS (A), FliD/FliT (B), $\mathrm{FlgK} / \mathrm{FlgN}(\mathbf{C})$, or FlgL/FlgN (D).

\subsection{Effect of the $\mathrm{FliH}_{2} /$ FliI Complex on Filament-Type Protein Export}

The $\mathrm{FliH}_{2} / \mathrm{FliI}$ complex greatly facilitates the export of rod/hook-type proteins such as FlgD and FlgE. The addition of the $\mathrm{FliH}_{2} / \mathrm{FliI}$ complex to the final concentration of $1.5 \mu \mathrm{M}$ to the assay solution increased the relative FlgD transport level 20-fold [29]. Therefore, we analyzed the impact of the 
$\mathrm{FliH}_{2} /$ FliI complex on filament-type protein export. The transport levels of the filament-type substrates were significantly increased by adding $1.5 \mu \mathrm{M} \mathrm{FliH}_{2} /$ FliI complex, similarly to FlgD export (Figure 3). These results suggest that the $\mathrm{FliH}_{2} / \mathrm{FliI}$ complex facilitates the export of filament-type proteins.

A
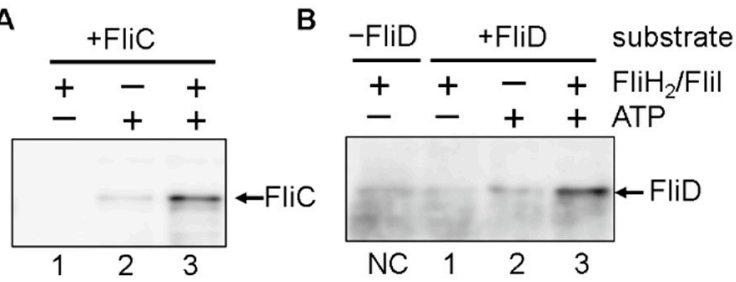

C

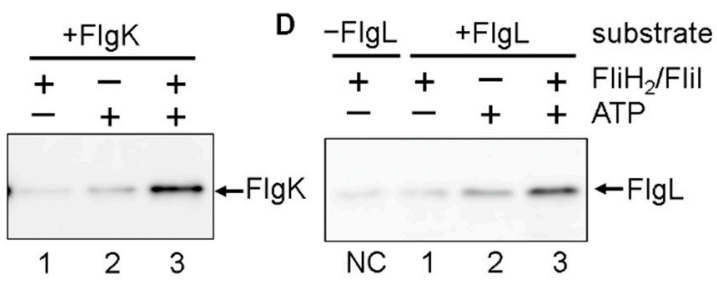

E

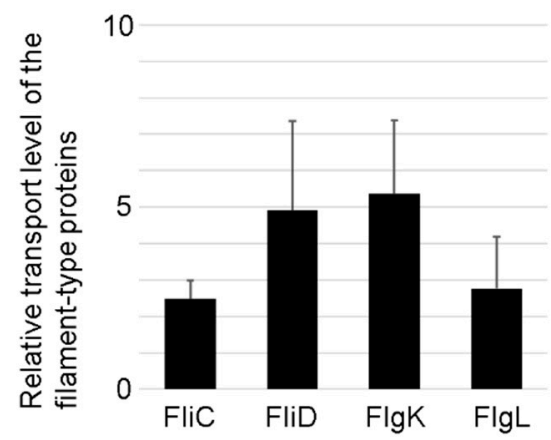

Figure 3. In vitro protein transport of the filament-type substrates into the IMVs. IMVs after completion of the hook were mixed with reaction mixture containing $0.25 \mu \mathrm{M}$ of FliJ and $2 \mu \mathrm{M}$ of the filament-type substrate-chaperone complex: FliC/FliS (A), FliD/FliT (B), FlgK/FlgN (C), and FlgL/FlgN (D). The transport assay was conducted with (+) or without (-) the $\mathrm{FliH}_{2} / \mathrm{FliI}_{\text {complex }}(1.5 \mu \mathrm{M})$ and ATP $(5 \mathrm{mM})$. The bands in Lane 1 in $(\mathbf{B}, \mathbf{C})$ are cross-reacting bands because similar bands were detected in the assay not containing the substrates (Lane NC in (B,C)). (E) The transport levels of the filament-type protein relative to those without the $\mathrm{FliH}_{2} / \mathrm{FliI}$ complex. The immunoblot band intensity was measured using Image J software. The relative transport level was calculated by dividing the band intensity of Lane 3 by that of Lane 2 after subtraction of that of Lane 1 (without ATP). Data from three independent experiments were averaged. Error bar represents standard deviation.

\subsection{Filament Structure Formation on the Hook in the IMVS}

We next examined whether the filament-type proteins exported into the IMVs formed the filament at the tip of the hook. We prepared the IMVs possessing the hook as shown above, and suspended them in an assay mixture containing the FlgN/FlgK, FlgN/FlgL, FliS/FliC, and FliT/FliD complexes $(1 \mu \mathrm{M}$ each), the FliH $_{2} /$ FliI complex $(1.5 \mu \mathrm{M})$, FliJ $(0.25 \mu \mathrm{M})$, ATP $(5 \mathrm{mM})$, and $\mathrm{Mg}^{2+}(5 \mathrm{mM})$. After incubation for $2 \mathrm{~h}$ at $37^{\circ} \mathrm{C}$, the IMVs were collected, washed and solubilized with detergent. Then the flagellar hook-basal bodies were precipitated by ultra-centrifugation, negatively stained with phosphotungstic acid, and observed by electron microscopy. We found the filament attached on the hook-basal body just like the filament-hook-basal body complex purified from Salmonella cells, indicating that the filament-type proteins and their cognate chaperones are sufficient to form the filament (Figure 4C) and no other soluble factor is needed for the protein export apparatus to coordinate the export of filament-type proteins with filament formation at the tip of the completed hook. The filament was not formed when either FliK or FlgE was absent in the reaction mixtures (Figure 4A,B), supporting the idea that the filament is formed only after completion of the hook. These results suggest that filament formation in the IMVs proceeded in the same way as in vivo.

We measured the length of the filament by electron microscopy. The filament length was widely distributed from 36 to $890 \mathrm{~nm}$, with an average length of $287 \mathrm{~nm}( \pm 166 \mathrm{~nm})$, suggesting that the filament length was not controlled (Supplementary Figure S2). The filaments formed in the IMVs were much shorter than those extended from the Salmonella cell body [34], implying that the filament growth was restricted by the inner space of the IMVs. Dynamic light scattering (DLS) measurement showed that the Z-average hydrodynamic radius of IMVs was $275 \mathrm{~nm} \pm 121$, which was consistent with the average lengths of the filaments formed in the IMVs. 
A

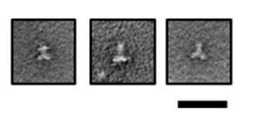

$100 \mathrm{~nm}$

B
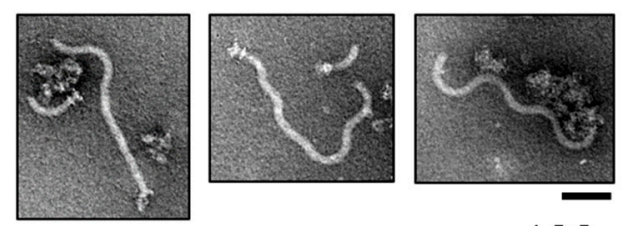

$100 \mathrm{~nm}$

C
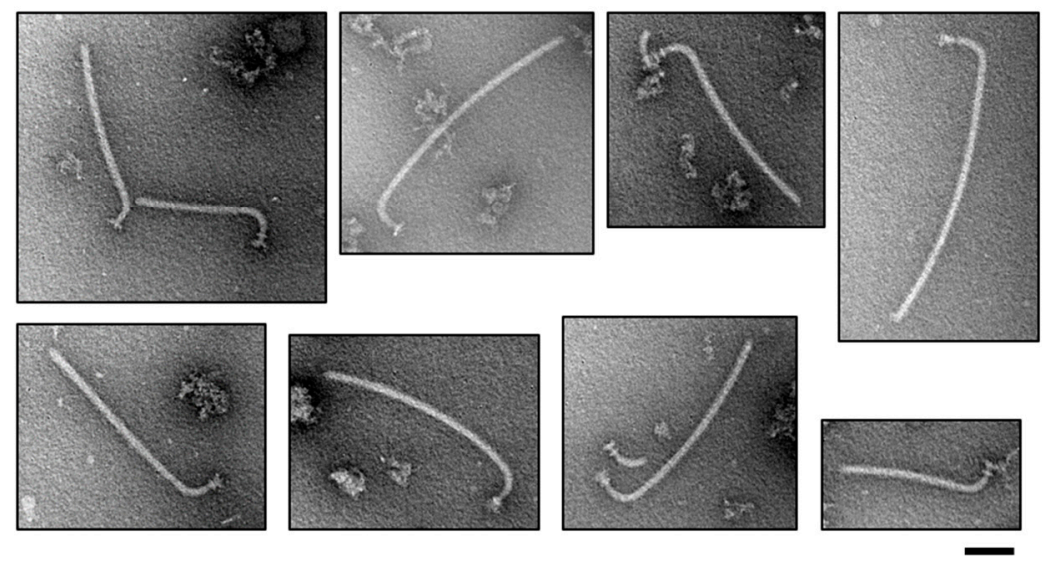

$100 \mathrm{~nm}$

Figure 4. Negative-staining electron micrographs of the basal bodies after transport assay of the filament-type proteins purified from the IMVs. The basal bodies after transport assay using the IMVs prepared after first reaction with FlgD and FliK but without FlgE (A), with FlgD and FlgE but without FliK (B), and with FlgD, FlgE, and FliK (C). The concentrations of FlgD, FlgE, FliK, FliH $2 / F_{1 i I}$ complex, FliJ, and ATP-Mg in the first reaction mixture were $4 \mu \mathrm{M}, 4 \mu \mathrm{M}, 4 \mu \mathrm{M}, 1.5 \mu \mathrm{M}, 0.25 \mu \mathrm{M}$, and $5 \mathrm{mM}$, respectively. The concentrations of FliC/FliS, FliD/FliT, FlgK/FlgN, and FlgL/FlgN in the transport assay mixture for the filament-type proteins were $1 \mu \mathrm{M}$ each and those of the $\mathrm{FliH}_{2} / \mathrm{FliI}$ complex, FliJ, and ATP-Mg were the same as in the first reaction mixture.

\subsection{Effect of Uncoupling of Flagellar Expression with Assembly on the Entire Assembly Process of the} Hook-Filament Complex in the IMVs

We also examined whether the entire process of hook-filament construction proceeded inside the IMVs without adding any soluble components other than those that were used in the above experiment. We prepared a transport assay mixture containing FlgD, FlgE, FliK ( $1 \mu \mathrm{M}$ each), the filament-type proteins in complex with their cognate chaperones $(1 \mu \mathrm{M}$ each), the ATPase complex proteins $(0.25 \mu \mathrm{M}$ FliJ and $1.5 \mu \mathrm{M} \mathrm{FliH} /$ FliI), ATP $(5 \mathrm{mM})$, and $\mathrm{Mg}^{2+}(5 \mathrm{mM})$. The IMVs were incubated in the mixture for $4 \mathrm{~h}$ at $37^{\circ} \mathrm{C}$, collected by ultra-centrifugation, washed, and solubilized with detergent. The flagellar axial structure was then precipitated by ultra-centrifugation and observed by electron microscopy. The hook-filament structure was formed on the basal body, indicating that the entire process of hook-filament formation proceeded inside the IMVs with only the protein components preexistent in the IMVs and those added in the external solution (Figure 5 and Supplementary Figure S3). This suggests that the coupling of gene expression with the flagellar assembly process is not essential for ordered flagellar formation, although it may be important for efficient construction of the flagellum. 

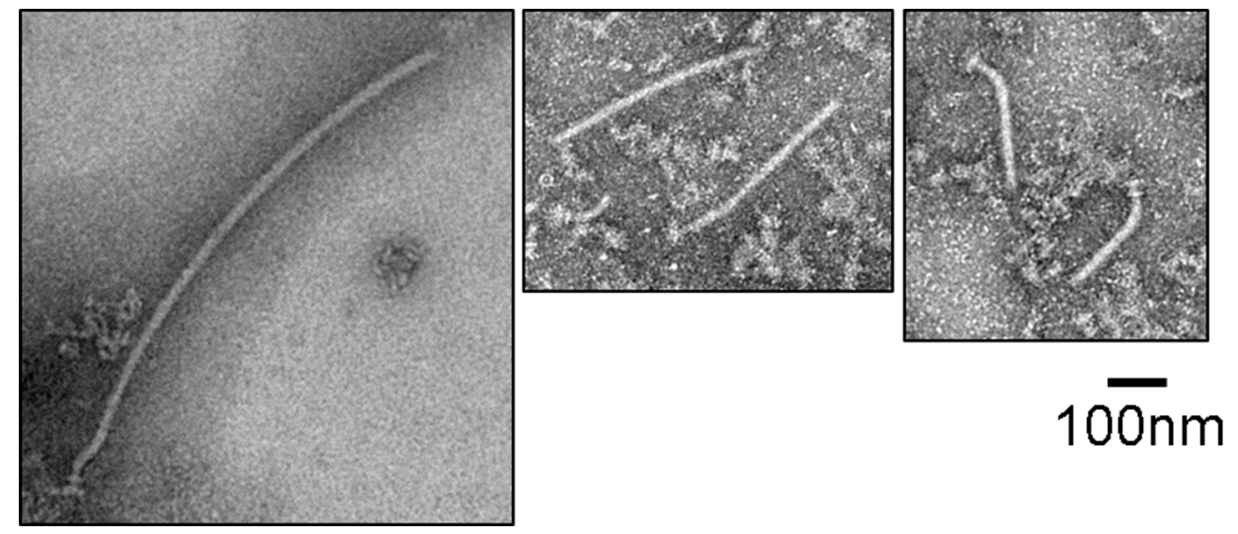

Figure 5. Autonomous hook-filament complex formation in the IMV. Negative-staining electron micrographs of the basal bodies after transport assay in the reaction mixture containing all the export proteins, their cognate chaperones, the export ATPase complex components, ATP, and $\mathrm{Mg}^{2+}$.

\section{Discussion}

The flagellar hook-filament complex has been reconstructed in solution using purified FlgK, FlgL, FliC, and FliD monomers, and purified hook fragments as a template [38]. However, this is just spontaneous self-assembly and is completely different from in vivo flagellar assembly, in which the assembly process is coupled with flagellar axial protein export. To understand protein export and the following assembly process, we developed an in vitro protein transport assay system that can reproduce the export and assembly process of the bacterial flagellar axial proteins that occur in living cells [29]. Our system uses IMVs and purified proteins. In a series of studies, we have demonstrated that the flagellar protein export apparatus in the IMVs preserves the transport activity of flagellar axial proteins. The hook-filament complex was successfully constructed from FlgD (hook-capping protein), FlgE (hook protein), FlgK (first junction protein), FlgL (second junction protein), FliC (filament protein, flagellin), and FliD (filament-capping protein) transported into the interior of the IMVs. Moreover, the important functions and events, such as hook length control and substrate specificity switch, were nicely reproduced in the IMVs. Thus, the IMV-based system is a powerful tool for investigating the mechanisms of flagellar protein export and assembly.

Our in vitro experiments using the IMVs clearly revealed that the substrate specificity switching of the flagellar protein export apparatus is triggered by FliK alone, and that no other factors are needed for the switching event. When the hook was preassembled inside the IMVs, the filament was formed on the hook without adding any proteins other than the filament components, their cognate chaperones, and the ATPase complex proteins. Moreover, the hook-filament structures were constructed in the IMVs even when all the necessary proteins and factors were added to the external solution at once. These results indicate that coordinated flagellar protein export is not obligately linked to the regulated flagellar gene expression, although they are coupled to each other in the living cell, probably for a more efficient assembly process.

Our results also suggest that the entire flagellar construction process, including the ordered protein export and assembly, is regulated by only the interactions of the PMF-driven export gate with the cytoplasmic ATPase complex, the export substrates, and export chaperones, without the involvement of any other factors. Although the ordered assembly of flagellar axial proteins is achieved in principle by a template-structure driven mechanism based on specific protein-protein interactions, an ordered protein export that could be caused by different affinities of export substrates for the export apparatus may play a role in increasing the assembly efficiency. In fact, the binding affinity of the substrate-chaperone complexes for the export apparatus correlates with the export order of the filament-type proteins [39]. FlgN and FliT interact with FliJ, whereas FliS does not [40]. The cytoplasmic domain of FlhA, one of the export gate component proteins, shows the highest binding affinity for the FlgN/FlgK and FlgN/FlgL complexes, a medium affinity for the FliT/FliD complex, and the lowest 
affinity for the FliS/FliC complex [41-43]. The filament-type proteins are believed to be secreted in the following order: first FlgK, followed by FlgL, FliD, and FliC. Since the filament was constructed on the hook in the IMVs when only supplying the filament-type substrate-chaperone complexes, the affinity of the substrate-chaperone complexes for the export apparatus may determine the export order of the filament-type substrates. However, our results showed that the individual substrates are also secreted in the absence of their predecessors, suggesting that the in vitro export order is not strict for the filamentous type proteins. It might be possible that transcriptional and translational regulation is needed to strictly control the secretion order in vivo.

All the filament-type proteins showed an increase in the export level upon the addition of the $\mathrm{FliH}_{2} /$ FliI complex in the assay solution (Figure 3). In addition, we found some differences in FliH-I-dependent export level between the filament-type proteins. It has been reported that FlgN and FliT interact with the $\mathrm{FliH}_{2} /$ FliI complex whereas FliS does not, suggesting that the $\mathrm{FliH}_{2} / \mathrm{FliI}_{\text {complex }}$ may be required for more efficient and rapid export of FlgK, FlgL, and FliD than FliC in vivo [39,44-47]. FlgK, FlgL, and FliD need to be assembled on the hook prior to FliC for filament formation. In the absence of FliH and FliI, a large amount of FliC is leaked into culture media [48], probably due to inefficient assembly of FlgK and FlgL on the hook caused by a failure in the ordered protein export. Therefore, the slight difference in the $\mathrm{FliH}_{2} / \mathrm{FliI}$ complex dependence of export may relate to the export order of the filament-type proteins.

The export signal of the substrate proteins is found in their disordered N-terminal region, although no significant common sequence has been identified in the region [49]. It has also been reported that the untranslated region of mRNA around the start codon of the substrates is also involved in substrate targeting to the export apparatus [50]. Our in vitro experiments, however, showed that the normal hook-filament structure was successfully constructed inside the IMVs in solution containing no mRNA. Thus, the substrate targeting signal of mRNA is not required for the export of the proteins necessary for hook-filament formation.

The flagellar export apparatus belongs to the type III secretion system family and shares high similarity with the bacterial pathogenic injectisome in its sequence, structure, and function. The injectisome serves to deliver virulence proteins called effectors into their host cells for their infection. The injectisome first exports the needle component proteins and switches the substrate specificity to deliver the effectors after completion of the needle part, just like the flagellum. Therefore, the IMV-based approach we presented here would be useful for studying virulence injectisomes as well.

\section{Conclusions}

We carried out in vitro flagellar protein transport assay to investigate the export process of the filament-type proteins and their assembly into the flagellar filament. The filament-type proteins were transported into the IMVs and formed the filament on the hook-basal body. The hook-filament structures were successfully formed inside the IMVs when all filament-type proteins, their cognate chaperone, FlgD, FlgE, FliK, the ATPase components, and ATP-Mg were simultaneously added into the assay solution. These results indicate that the coordinated flagellar construction is regulated only by the interactions between the flagellar protein export apparatus, the export substrate proteins, and their cognate chaperones.

Supplementary Materials: The following are available online at http://www.mdpi.com/2218-273X/10/1/126/s1, Table S1: Primer list for this study. Figure S1: SDS-PAGE analysis of purified proteins used in the in this study. Figure S2: Length distribution of the filament formed on the hook in the IMVs. Figure S3: Magnified electron microscopic image of the hook-filament junction region of the hook-filament complex constructed in the IMV.

Author Contributions: Conceptualization, H.T. and K.I.; methodology, H.T. and K.I.; validation, H.T., C.T. and K.I.; formal analysis, H.T., K.N., T.M. and K.I.; investigation, H.T., C.T. and A.K.; resources, H.T., K.N., T.M. and K.I.; data curation, H.T. and K.I.; writing—original draft preparation, H.T. and K.I.; writing—review and editing, H.T., K.N., T.M. and K.I.; visualization, H.T.; supervision, K.I.; project administration, K.I.; funding acquisition, H.T., K.N., T.M. and K.I. All authors have read and agree to the published version of the manuscript. 
Funding: This work was supported in part by JSPS KAKENHI Grant Numbers JP18K07108 (to H.T.), JP15H02386 (to K.I.), JP21227006 and JP25000013 (to K.N.), and JP26293097 and JP19H03182 (to T.M.), and MEXT KAKENHI Grant Numbers JP23115008 (to K.I.), and JP15H01640 (to T.M.), and Platform Project for Supporting Drug Discovery and Life Science Research (BINDS) from AMED under Grant Number JP19am0101117 (to K.N.), and the Public Foundation of Chubu Science and Technology Center Grant (to H.T.). This work also supported by JEOL YOKOGUSHI Research Alliance Laboratories of Osaka University to K.N.

Acknowledgments: We thank S. Kobashi and M. Kinoshita for technical support in purification of proteins, R. Yonehara, A. Nakagawa and K. Togon for technical support in DLS, and K. Maki for technical support for EM observation.

Conflicts of Interest: The authors declare no conflict of interest.

\section{References}

1. Macnab, R.M. How bacteria assemble flagella. Annu. Rev. Microbiol. 2003, 57, 77-100. [CrossRef] [PubMed]

2. Minamino, T. Protein export through the bacterial flagellar type III export pathway. Biochim. Biophys. Acta 2014, 1843, 1642-1648. [CrossRef]

3. Terashima, H.; Kojima, S.; Homma, M. Flagellar motility in bacteria: Structure and function of flagellar motor. Int. Rev. Cell. Mol. Biol. 2008, 270, 39-85. [PubMed]

4. Iino, T. Assembly of Salmonella flagellin in vitro and in vivo. J. Supramol. Struct. 1974, 2, 372-384. [PubMed]

5. Zhao, Z.; Zhao, Y.; Zhuang, X.Y.; Lo, W.C.; Baker, M.A.B.; Lo, C.J.; Bai, F. Frequent pauses in Escherichia coli flagella elongation revealed by single cell real-time fluorescence imaging. Nat. Commun. 2018, 9, 1885. [CrossRef] [PubMed]

6. Chen, S.; Beeby, M.; Murphy, G.E.; Leadbetter, J.R.; Hendrixson, D.R.; Briegel, A.; Li, Z.; Shi, J.; Tocheva, E.I.; Müller, A.; et al. Structural diversity of bacterial flagellar motors. EMBO J. 2011, 30, 2972-2981. [CrossRef]

7. Kawamoto, A.; Morimoto, Y.V.; Miyata, T.; Minamino, T.; Hughes, K.T.; Kato, T.; Namba, K. Common and distinct structural features of Salmonella injectisome and flagellar basal body. Sci. Rep. 2013, 3, 3369. [CrossRef]

8. Minamino, T.; Doi, H.; Kutsukake, K. Substrate specificity switching of the flagellum-specific export apparatus during flagellar morphogenesis in Salmonella typhimurium. Biosci. Biotechnol. Biochem. 1999, 63, 1301-1303. [CrossRef]

9. Hirano, T.; Minamino, T.; Namba, K.; Macnab, R.M. Substrate specificity classes and the recognition signal for Salmonella type III flagellar export. J. Bacteriol. 2003, 185, 2485-2492. [CrossRef]

10. Hirano, T.; Yamaguchi, S.; Oosawa, K.; Aizawa, S. Roles of FliK and FlhB in determination of flagellar hook length in Salmonella typhimurium. J. Bacteriol. 1994, 176, 5439-5449. [CrossRef]

11. Moriya, N.; Minamino, T.; Hughes, K.T.; Macnab, R.M.; Namba, K. The type III flagellar export specificity switch is dependent on FliK ruler and a molecular clock. J. Mol. Biol. 2006, 359, 466-477. [CrossRef] [PubMed]

12. Shibata, S.; Takahashi, N.; Chevance, F.F.; Karlinsey, J.E.; Hughes, K.T.; Aizawa, S. FliK regulates flagellar hook length as an internal ruler. Mol. Microbiol. 2007, 64, 1404-1415. [CrossRef] [PubMed]

13. Kutsukake, K.; Minamino, T.; Yokoseki, T. Isolation and characterization of FliK-independent flagellation mutants from Salmonella typhimurium. J. Bacteriol. 1994, 176, 7625-7629. [CrossRef] [PubMed]

14. Williams, A.W.; Yamaguchi, S.; Togashi, F.; Aizawa, S.I.; Kawagishi, I.; Macnab, R.M. Mutations in fliK and $f l h B$ affecting flagellar hook and filament assembly in Salmonella typhimurium. J. Bacteriol. 1996, 178, 2960-2970. [CrossRef] [PubMed]

15. Minamino, T.; González-Pedrajo, B.; Yamaguchi, K.; Aizawa, S.I.; Macnab, R.M. FliK, the protein responsible for flagellar hook length control in Salmonella, is exported during hook assembly. Mol. Microbiol. 1999, 34, 295-304. [CrossRef]

16. Erhardt, M.; Singer, H.M.; Wee, D.H.; Keener, J.P.; Hughes, K.T. An infrequent molecular ruler controls flagellar hook length in Salmonella enterica. EMBO J. 2011, 30, 2948-2961. [CrossRef]

17. Hirano, T.; Shibata, S.; Ohnishi, K.; Tani, T.; Aizawa, S. N-terminal signal region of FliK is dispensable for length control of the flagellar hook. Mol. Microbiol. 2005, 56, 346-360. [CrossRef]

18. Minamino, T.; Ferris, H.U.; Moriya, N.; Kihara, M.; Namba, K. Two parts of the T3S4 domain of the hook-length control protein FliK are essential for the substrate specificity switching of the flagellar type III export apparatus. J. Mol. Biol. 2006, 362, 1148-1158. [CrossRef] 
19. Kinoshita, M.; Aizawa, S.-I.; Inoue, Y.; Namba, K.; Minamino, T. The role of intrinsically disordered C-terminal region of FliK in substrate specificity switching of the bacterial flagellar type III export apparatus. Mol. Microbiol. 2017, 105, 572-588. [CrossRef]

20. Terahara, N.; Inoue, Y.; Kodera, N.; Morimoto, Y.V.; Uchihashi, T.; Imada, K.; Ando, T.; Namba, K.; Minamino, T. Insight into structural remodeling of the FlhA ring responsible for bacterial flagellar type III protein export. Sci. Adv. 2018, 4, eaao7054. [CrossRef]

21. Inoue, Y.; Ogawa, Y.; Kinoshita, M.; Terahara, N.; Shimada, M.; Kodera, N.; Ando, T.; Namba, K.; Kitao, A.; Imada, K.; et al. Structural insight into the substrate specificity switch mechanism of the type III protein export apparatus. Structure 2018, 27, 965-976. [CrossRef] [PubMed]

22. Minamino, T.; Inoue, Y.; Kinoshita, M.; Namba, K. FliK-driven conformational rearrangements of FlhA and FlhB are rquired for export switching of the flagellar potein export apparatus. J. Bacteriol. 2020, 202. [CrossRef]

23. Fraser, G.M.; Bennett, J.C.; Hughes, C. Substrate-specific binding of hook-associated proteins by FlgN and FliT, putative chaperones for flagellum assembly. Mol. Microbiol. 1999, 32, 569-580. [CrossRef] [PubMed]

24. Auvray, F.; Thomas, J.; Fraser, G.M.; Hughes, C. Flagellin polymerisation control by a cytosolic export chaperone. J. Mol. Biol. 2001, 308, 221-229. [CrossRef] [PubMed]

25. Aldridge, P.; Karlinsey, J.; Hughes, K.T. The type III secretion chaperone FlgN regulates flagellar assembly via a negative feedback loop containing its chaperone substrates FlgK and FlgL. Mol. Microbiol. 2003, 49, 1333-1345. [CrossRef] [PubMed]

26. Yokoseki, T.; Iino, T.; Kutsukake, K. Negative regulation by fliD, fliS, and fliT of the export of the flagellum-specific anti-sigma factor, FlgM, in Salmonella typhimurium. J. Bacteriol. 1996, 178, 899-901. [CrossRef] [PubMed]

27. Karlinsey, J.E.; Lonner, J.; Brown, K.L.; Hughes, K.T. Translation/secretion coupling by type III secretion systems. Cell 2000, 102, 487-497. [CrossRef]

28. Yamamoto, S.; Kutsukake, K. FliT acts as an anti-FlhD $\mathrm{C}_{2}$ factor in the transcriptional control of the flagellar regulon in Salmonella enterica serovar typhimurium. J. Bacteriol. 2006, 188, 6703-6708. [CrossRef]

29. Terashima, H.; Kawamoto, A.; Tatsumi, C.; Namba, K.; Minamino, T.; Imada, K. In vitro reconstitution of functional type III protein export and insights into flagellar assembly. MBio 2018, 9. [CrossRef]

30. Terashima, H.; Imada, K. Novel insight into an energy transduction mechanism of the bacterial flagellar type III protein export. Biophys. Phys. 2018, 15, 173-178. [CrossRef]

31. Minamino, T.; Namba, K. Distinct roles of the FliI ATPase and proton motive force in bacterial flagellar protein export. Nature 2008, 451, 485-488. [CrossRef] [PubMed]

32. Paul, K.; Erhardt, M.; Hirano, T.; Blair, D.F.; Hughes, K.T. Energy source of flagellar type III secretion. Nature 2008, 451, 489-492. [CrossRef] [PubMed]

33. Minamino, T.; Morimoto, Y.V.; Hara, N.; Namba, K. An energy transduction mechanism used in bacterial flagellar type III protein export. Nat. Commun. 2011, 2, 475. [CrossRef] [PubMed]

34. Minamino, T.; Morimoto, Y.V.; Kinoshita, M.; Aldridge, P.D.; Namba, K. The bacterial flagellar protein export apparatus processively transports flagellar proteins even with extremely infrequent ATP hydrolysis. Sci. Rep. 2014, 4, 7579. [CrossRef]

35. Ibuki, T.; Imada, K.; Minamino, T.; Kato, T.; Miyata, T.; Namba, K. Common architecture of the flagellar type III protein export apparatus and F- and V-type ATPases. Nat. Struct. Mol. Biol. 2011, 18, 277-282. [CrossRef]

36. Imada, K.; Minamino, T.; Uchida, Y.; Kinoshita, M.; Namba, K. Insight into the flagella type III export revealed by the complex structure of the type III ATPase and its regulator. Proc. Natl. Acad. Sci. USA 2016, 113, 3633-3638. [CrossRef]

37. Kinoshita, M.; Nakanishi, Y.; Furukawa, Y.; Namba, K.; Imada, K.; Minamino, T. Rearrangements of $\alpha$-helical structures of FlgN chaperone control the binding affinity for its cognate substrates during flagellar type III export. Mol. Microbiol. 2016, 101, 656-670. [CrossRef]

38. Ikeda, T.; Asakura, S.; Kamiya, R. Total reconstitution of Salmonella flagellar filaments from hook and purified flagellin and hook-associated proteins in vitro. J. Mol. Biol. 1989, 209, 109-114. [CrossRef]

39. Minamino, T. Hierarchical protein export mechanism of the bacterial flagellar type III protein export apparatus. FEMS Microbiol. Lett. 2018, 365, 117. [CrossRef]

40. Evans, L.D.; Stafford, G.P.; Ahmed, S.; Fraser, G.M.; Hughes, C. An escort mechanism for cycling of export chaperones during flagellum assembly. Proc. Natl. Acad. Sci. USA 2006, 103, 17474-17479. [CrossRef] 
41. Minamino, T.; Kinoshita, M.; Hara, N.; Takeuchi, S.; Hida, A.; Koya, S.; Glenwright, H.; Imada, K.; Aldridge, P.D.; Namba, K. Interaction of a bacterial flagellar chaperone FlgN with FlhA is required for efficient export of its cognate substrates. Mol. Microbiol. 2012, 83, 775-788. [CrossRef] [PubMed]

42. Kinoshita, M.; Hara, N.; Imada, K.; Namba, K.; Minamino, T. Interactions of bacterial flagellar chaperonesubstrate complexes with FlhA contribute to co-ordinating assembly of the flagellar filament. Mol. Microbiol. 2013, 90, 1249-1261. [CrossRef] [PubMed]

43. Bange, G.; Kümmerer, N.; Engel, C.; Bozkurt, G.; Wild, K.; Sinning, I. FlhA provides the adaptor for coordinated delivery of late flagella building blocks to the type III secretion system. Proc. Natl. Acad. Sci. USA 2010, 107, 11295-11300. [CrossRef] [PubMed]

44. Thomas, J.; Stafford, G.P.; Hughes, C. Docking of cytosolic chaperone-substrate complexes at the membrane ATPase during flagellar type III protein export. Proc. Natl. Acad. Sci. USA 2004, 101, 3945-3950. [CrossRef]

45. Imada, K.; Minamino, T.; Kinoshita, M.; Furukawa, Y.; Namba, K. Structural insight into the regulatory mechanisms of interactions of the flagellar type III chaperone FliT with its binding partners. Proc. Natl. Acad. Sci. USA 2010, 107, 8812-8817. [CrossRef]

46. Minamino, T.; Kinoshita, M.; Imada, K.; Namba, K. Interaction between FliI ATPase and a flagellar chaperone FliT during bacterial flagellar protein export. Mol. Microbiol. 2012, 83, 168-178. [CrossRef]

47. Sajó, R.; Liliom, K.; Muskotál, A.; Klein, A.; Závodszky, P.; Vonderviszt, F.; Dobó, J. Soluble components of the flagellar export apparatus, FliI, FliJ, and FliH, do not deliver flagellin, the major filament protein, from the cytosol to the export gate. Biochim. Biophys. Acta 2014, 1843, 2414-2423. [CrossRef]

48. Inoue, Y.; Morimoto, Y.V.; Namba, K.; Minamino, T. Novel insights into the mechanism of well-ordered assembly of bacterial flagellar proteins in Salmonella. Sci. Rep. 2018, 8, 1787. [CrossRef]

49. Végh, B.M.; Gál, P.; Dobó, J.; Závodszky, P.; Vonderviszt, F. Localization of the flagellum-specific secretion signal in Salmonella flagellin. Biochem. Biophys. Res. Commun. 2006, 345, 93-98. [CrossRef]

50. Singer, H.M.; Erhardt, M.; Hughes, K.T. Comparative analysis of the secretion capability of early and late flagellar type III secretion substrates. Mol. Microbiol. 2014, 93, 505-520. [CrossRef]

(C) 2020 by the authors. Licensee MDPI, Basel, Switzerland. This article is an open access article distributed under the terms and conditions of the Creative Commons Attribution (CC BY) license (http://creativecommons.org/licenses/by/4.0/). 